\title{
Science budget faces continuing squeeze in South Africa
}

Cape Town. South African scientists have been disappointed at the new science budget, which will be increased by only 1.8 per cent in the 1995-96 financial year, to a total of R834 million (US\$230 million). It had been hoped that the creation of a new ministry responsible for science might have prevented a further erosion of spending on science, which fell by 27 per cent between 1987 and last year.

The increase in the science vote is less than the average spending increases of just over seven per cent granted to government departments as a whole. The total budget increase is in line with the expected level of inflation; but a large proportion will be taken up servicing the national debt.

Despite his commitment to increasing expenditure on research and development, Ben Ngubane, the Minister of Arts, Culture, Science and Technology, has clearly failed to persuade his cabinet colleagues to boost funding this year. Nor has he been able to introduce any transparency into the process of allocating the science vote among the research councils.

As with the Scientific Advisory Council appointed by the previous National Party government, the recommendations of the minister's interim advisory committee were not made public. It is therefore unclear whether the differing increases awarded to the various councils reflect the views of this committee or those of the ministerial committee that makes the final allocations.

The biggest increases this year were awarded to the two largest councils, the Council for Scientific and Industrial Research and the Agricultural Research Council, which both carry out in-house research. They received increases of 5.9 per cent and 6.3 per cent respectively, effectively reversing the effects of last year's trend, when they received the smallest rises.

By contrast, the Foundation for Research and Development and the Medical Research Council, the two councils that distribute a significant proportion of their funds to the tertiary education sector, each received funding increases of only 2.7 per cent. The Council for Geosciences was given a budget increase of 4.5 per cent.

\section{Michael Cherry}

- President Nelson Mandela has dismissed his wife Winnie as deputy minister of Arts, Culture, Science and Technology, and replaced her in this post with Brigitte Mabandla, a Member of Parliament who represents the African National Congress. Mabandla is a prominent feminist and a former exile. She is a lawyer by training, and appears to be a popular choice to succeed Mrs Mandela.

\section{Aerosols' role simulated in new global warming model}

London. Scientists at the UK Meteorological Office's Hadley Centre claimed success last week in their efforts to develop a computer model which accurately simulates the way in which aerosols mitigate the process of global warming.

According to the scientists, preliminary results circulated to delegates attending the first full governmental meeting of signatories to the Climate Change Convention, signed in Rio de Janeiro in 1992, suggests that, for the first time, a general Circulation Model has been able to replicate in broad terms observed temperature changes over the past 130 years (see figure).

Previous studies by the International Panel on Climate Change (IPCC) showed that greenhouse gases acting on their own would have led to an increase in global temperature of between 0.6 and $1.3^{\circ}$ Centigrade over this period.

An experiment based on the new model, taking into account the emissions of natural

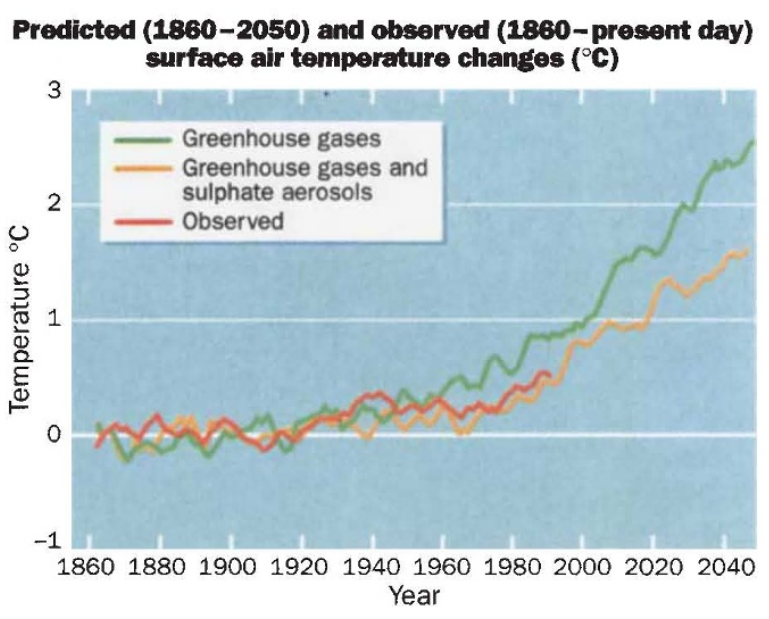
value of $0.5^{\circ} \mathrm{C}$.

and man-made sulphates, produced a simulated temperature rise close to the observed

"What we have done is reduce the uncertainty of the models," says David Bennetts of the Hadley Centre. "The important thing is that you can put the aerosols in, and the model appears to behave close to what is observed." A report circulated at Berlin by UK officials describes the experiment with the model, which took three months to run on supercomputers, as "an important step forward in climate prediction science."

At the same time, they acknowledge that more work needs to be done on, for example, the fact that regional calculations with the model show a greater variability from observed temperature changes than the global model. "It is clear that the location and magnitude of specific changes are not replicated fully - as might be expected from this first attempt to allow for the influence of aerosols," the scientists state in last week's report (a full paper describing the results of running the model has been submitted to Nature).

But the models already indicate that the role of aerosols in climate change may have important policy implications. For example, the fact that regional reductions in sulphate aerosol emissions can, according to the model, lead to local temperature increases is likely to cause a dilemma to governments faced with pressure to take just such action in order to reduce the dangers of acid rain. David Dickson

\section{Major ozone thinning found over Arctic}

London. A joint European research project has detected new evidence of a significant reduction in ozone levels in the atmosphere, this time over the Arctic. But the researchers say they remain uncertain how much of the reduction is due to ozone depleting chemicals, rather than to dynamic changes caused by the mixing of air masses at different ozone levels.

Analysis of both ground and air-based observations by the Second European Stratospheric Arctic and Mid-latitude Experiment (SESAME) over the Arctic polar vortex - a moving body of cold air found mostly above northern Europe has revealed a reduction of up to $\mathbf{5 0}$ per cent in ozone levels at altitudes between 16 and 18 kilometres.
"A large part of this difference is likely to be caused by the chemical destruction of ozone," the SESAME team said in a statement last week. "But further analysis is required to quantify and confirm this."

SESAME is a two-year experiment funded by the European Union to look at the causes of ozone depletion in the northern hemisphere. The researchers found ozone levels in parts of the polar vortex falling at about 0.7 per cent a day. They point out that the amount of ozone over middle latitudes in the northern hemisphere has declined by more than seven per cent over the last 15 years.

SESAME's measurement phase is now nearing completion. It will be followed by a period of intensive analysis.

E. M. 